\title{
Spectrophotometric Studies on the Protonation and Nickel Complexation Equilibria of 4-(2-Pyridylazo) Resorcinol using Global Analysis in Aqueous Solution
}

\author{
Jahanbakhsh Ghasemi, ${ }^{*, a}$ Ali Niazi ${ }^{b}$ and Marcel Maeder ${ }^{c}$ \\ ${ }^{a}$ Department of Chemistry, Faculty of Sciences, Razi University, Kermanshah, Iran \\ ${ }^{b}$ Department of Chemistry, Faculty of Sciences, Azad University of Arak, Arak, Iran \\ ${ }^{c}$ Department of Chemistry, University of Newcastle, Callaghan, Australia
}

\begin{abstract}
A protonação e complexação de Ni(II) por 4-(2-piridilazo) resorcinol (PAR) em força iônica $0,1 \mathrm{~mol} \mathrm{~L}^{-1} \mathrm{KNO}_{3}$ a $25^{\circ} \mathrm{C}$, foram estudadas por análise global. Em titulações espectrofotométricas, a dependência linear ou quase linear da concentração e a existência de espécies em menores concentrações podem causar dificuldades na avaliação dos dados. Espectros de absorção e as correspondentes constantes de equilíbrio calculadas ou são desconhecidos ou mal estabelecidos. Dessa forma, torna-se difícil ajustar um modelo confiável aos dados. Na análise global de segunda ordem, titulações espectrofotométricas com diferentes concentrações iniciais são simultaneamente analisadas. Assim, condições para a formação signifitiva de todas as espécies podem ser obtidas e, conseqüentemente, a matriz de concentração é completada. EQUISPEC é um programa computacional que usa matriz gerada em ambiente MATLAB para análise global de segunda ordem de dados espectrofotométricos. As titulações espectrofotométricas foram efetuadas, no mínimo, para quatro diferentes valores da razão metal-ligante.
\end{abstract}

The protonation and $\mathrm{Ni}$ (II) complexation of 4-(2-pyridylazo) resorcinol (PAR) in ionic strength $0.1 \mathrm{~mol} \mathrm{~L}^{-1} \mathrm{KNO}_{3}$ at $25{ }^{\circ} \mathrm{C}$ has been studied by global analysis. In spectrophotometric titrations, linear or near-linear dependence of concentration profiles and the existence of minor species can cause difficulties in the evaluation of the data. Both calculated absorption spectra and the corresponding equilibrium constants are not or only poorly defined. The result is the inability to reliably fit a reasonable model to the data. In second order global analysis, a number of spectrophotometric titrations with different initial concentrations are simultaneously analyzed. In this way, conditions for the significant formation of all species can be obtained and consequently the concentration matrix is augmented to full rank. EQUISPEC is a computer program using the matrix based MATLAB environment for second order global analysis of spectrophotometric equilibrium data. The spectrophotometric titrations were carried out at least in four different metal to ligand ratios.

Keywords: PAR, nickel, protonation equilibrium, stability constants, global analysis, $\mathrm{pH}$-absorbance titration

\section{Introduction}

The accurate determination of acidity and stability constants values are fundamental to understanding the behavior of ligands and their interaction with metal ions in aqueous solution. Such an understanding is important in a wide variety of areas, such as metal ions in biology, in biomedical applications, metal ions in the environment, extraction metallurgy, food chemistry and metal ions in many industrial processes. ${ }^{1,2}$ One specific application is

*e-mail: jahan.ghasemi@gmail.com; ali.niazi@gmail.com the use of chelating agents in heavy metal ion in toxication treatment. It is a very complex field that requires the collaboration of several branches of science. The main contribution of chemistry to this field is the determination of formation constants of complexes between metal ions and chelating agents to compare the strength and characteristics of the formed complexes. ${ }^{3,4}$

Spectrophotometry is one of the most powerful methods for the investigation of solution equilibria, although potentiometric $\mathrm{pH}$ titrations are more convenient and more commonly used due to the simplicity of equipment and minimal time 
requirements. However, potentiometry is useful only for determining equilibria in the approximate $\mathrm{pH}$ range of 2.5-11, whereas spectrophotometric titrations are not limited to any $\mathrm{pH}$ range. In contrast to potentiometric titrations, where only equilibrium constants are produced, spectrophotometric titrations also yield additional spectral information about the species formed during the titration. This supports a structural analysis of the compounds. Spectrophotometric titrations are also useful in discriminating between different equilibrium models. ${ }^{5}$

In a spectrophotometric titration, controlled displacement of a chemical equilibrium occurs through the addition of titrant. In most investigations in aqueous solution the titrant is a strong base or acid and the measurement produces absorbance data which is a collection of absorption spectra as a function of $\mathrm{pH}$. It is most convenient to arrange the series of measured absorption spectra, as function wavelengths at different $\mathrm{pH}$ values as the rows of a matrix $\mathbf{Y}$. According to BeerLambert's law, $\mathbf{Y}$ can be decomposed into the product of a concentration matrix $\mathbf{C}$ and a matrix $\mathbf{A}$ of molar absorptivities. The concentration profiles of the absorbing species form the columns of $\mathbf{C}$; the molar absorption spectra form the corresponding rows of $\mathbf{A}$. Due to instrumental and experimental errors, this decomposition is not perfect, the difference being the matrix $\mathbf{E}$ of residuals. A matrix equation can be written as:

\section{$\mathbf{Y}=\mathbf{C A}+\mathbf{E}$}

Data fitting consists of determining those unknown parameters for which the sum of the squares over all elements of the matrix $\mathbf{E}$ of residuals is minimal. Initially, the unknown parameters include the equilibrium constants, a vector $\mathbf{p}$ of non-linear parameters, overall formation constants, and all the molar absorptivities of all the components, i.e. the complete matrix $\mathbf{A}$ of linear parameters. $\mathbf{C}$ is defined by the model and the appropriate equilibrium constants and is calculated numerically using the law of mass action and the analytical (total) concentrations of each component in solution. ${ }^{6-9}$ If spectra are measured at many wavelengths, the total number of parameters can be very high and it is crucial to reduce this number by separation of the linear and non-linear parameters. For any set of non-linear parameters, $\mathbf{p}$, which defines the concentration matrix $\mathbf{C}$, the best set of linear parameters, the matrix $\hat{\mathbf{A}}$, is an explicit least-squares calculation:

$\hat{\mathbf{A}}=\mathbf{C}^{+} \mathbf{Y}$
$\mathbf{C}^{+}$is the pseudo-inverse which can be calculated as $\mathbf{C}^{+}=\left(\mathbf{C}^{\mathbf{t}} \mathbf{C}\right)^{-1} \mathbf{C}^{\mathrm{t}}$ or preferably using a numerically more stable algorithm (i.e., an algorithm which guarantee to reach a physically meaningful final results), ${ }^{10} \hat{\mathbf{A}}$ is now defined as a function of $\mathbf{p}$, and consequently $\mathbf{E}$ and the sum of squares (ssq) are defined as a function of the nonlinear parameters only:

$s s q=\Sigma \Sigma E(i, j)^{2}=f(Y$, model, parameters $)=f(p)$

In equilibrium studies, the model is the collection of equilibria between the component species and the parameters are the equilibrium constants. The computation of the pseudo-inverse $\mathbf{C}^{+}$seems to be a trivial task. In equilibrium studies, generally the concentration matrix C has, at least theoretically, full rank, i.e., the chemical and mathematical ranks are equal, and the concentration profiles for all species are linearly independent. $\mathbf{C}^{+}$can be computed and $\hat{\mathbf{A}}$ is determined by equation (2). This is, however, not always the case and near linear dependency (i.e. when the distribution diagram of some species can be expressed as linear combination of some other species) and/or species with only very low concentrations, results in deficiencies in the equilibrium model. In this status, $\mathbf{C}$, then, does not have full rank and the pseudo-inverse, $\mathbf{C}^{+}$, is not or is only poorly defined, which can render its computation of $\mathbf{C}^{+}$difficult to impossible and thus corrupt the resulting $\hat{\mathbf{A}}$ as well as the residuals, $\mathbf{E}$, and the sum of squares. There are powerful algorithms such as Newton-Gauss-Levenberg/Marquardt algorithm available for this task and interested reader may refer to the literature for detailed descriptions. ${ }^{11}$

A generally applicable method for the investigation of systems which suffer from rank deficiency (the mathematical rank is smaller than the number of radiation absorbing species in the system) data sets and/or poorly defined equilibria of minor species has been reported. ${ }^{12}$ The method involves simultaneous, global analysis of a series of spectrophotometric titrations, each performed under different initial conditions such as in different $\mathrm{pH}$ or concentration that was called second order global analysis. The term globalization has been coined for the analysis of multichannel/multiwavelength data sets. ${ }^{13-15}$ It has been recognized and subsequently verified experimentally that the global analysis, where the spectral series is treated as a unity, is superior to the alternative way of analyzing the trace at individual wavelengths separately and subsequent treatment of the individual results. ${ }^{16}$

In this study, protonation and nickel complexation by 4-(2-pyridylazo) resorcinol (Scheme 1 and 2 for PAR 
and expected metal complex) was investigated as a new application of global analysis to the photometric titrations in solution equilibria studies. Second order global analysis proved useful by combining and simultaneously analyzing data for metal: ligand ratios of $0: 1,1: 1$, and $1: 2$. The concentration profiles are slightly different for each ratio, so while measurements of one ratio does show linear dependence; the combination of all the measurements contains adequate information for successful analysis of the system. The global analysis of the photometric titration data has profound advantages over the other methods like potentiometric titration in which the calculations of the ligand acidity constants and metal complexes formation constants are performed in separate experiments. As a result, error multiplications cause more uncertainty in the obtained equilibrium constants in comparison to the global analysis.

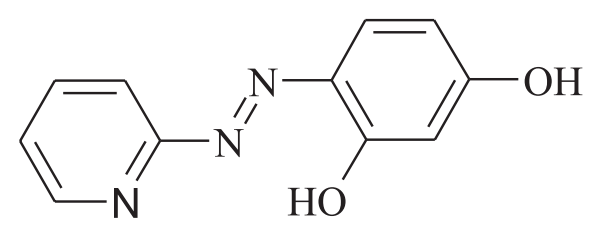

Scheme 1.

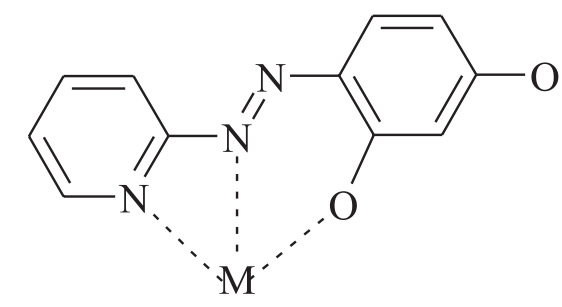

Scheme 2.

\section{Experimental}

Reagents

All the chemicals used were of analytical-reagent grade; triple distilled water was used throughout. Stock solution of nickel (II) were prepared from nickel nitrate hexahydrate (Merck) and standardized titrimetrically. Reference solutions were made by appropriate dilution daily as required. A stock $10^{-4} \mathrm{~mol} \mathrm{~L} \mathrm{~L}^{-1}$ solution of 4-(2pyridylazo) resorcinol (PAR) (Merck) solution was prepared by dissolving reagent in triply distilled water at acidified $\mathrm{pH}<2.0(\mathrm{HCl})$. Reagent grade hydrochloric acid (Merck), sodium hydroxide (Merck) and potassium nitrate (Merck) were of the highest purity available and used without further purification.

\section{Spectrophotometric titrations}

For the Ni/PAR titrations, absorption spectra were measured with an automatic titration set-up consisting of a computer interfaced to a CECIL 9000 spectrophotometer, automatic stirrer, Metrohm 665 Dosimat automatic burette with 5 dispenser unit, a second syringe-burette, and a $\mathrm{pH}$ electrode. After each $\mathrm{pH}$ adjustment, solution is transferred into the cuvette and the absorption spectrum is recorded. The pH-meter was calibrated with at least three buffer solutions at $\mathrm{pH}$ 4.00, 7.00 and 11.00 (Reagecon Product labels). The uncertainty associated with these $\mathrm{pH}$ values are $\pm 0.01 \mathrm{pH}$ unit. Ionic strength was maintained at 0.1 mol L-1 by adding appropriate amounts of $\mathrm{KNO}_{3}$.

\section{Protonation constants of 4-(2-pyridylazo) resorcinol}

The protonation constants were easily obtained in $\mathrm{pH}$ range $2-13$ by the automatic titration apparatus at $25 \pm 0.5{ }^{\circ} \mathrm{C}$ and $\mathrm{I}=0.1 \mathrm{~mol} \mathrm{~L}^{-1}\left(\mathrm{KNO}_{3}\right)$. The desired increment in $\mathrm{pH}$ was obtained by incremental addition of the $\mathrm{NaOH}$ solution. After each increment the solution was left to completely homogenize and the reading of the $\mathrm{pH}$ values carried out when the differential changes in $\mathrm{pH}$ was less than about $1 \%$ of its relative value. The analytical concentration of ligand in the cell was $4.4 \times$ $10^{-5} \mathrm{~mol} \mathrm{~L}^{-1}$. The spectral measurements were carried out between 380 and $600 \mathrm{~nm}$ with $6 \mathrm{~nm}$ intervals.

\section{Stability constants of Ni-PAR system}

The complexation of $\mathrm{Ni}^{2+}$ by 4-(2-pyridylazo) resorcinol (PAR) has been studied by titrating mixtures of $\mathrm{Ni}$ $\left(\mathrm{NO}_{3}\right)_{2} \cdot 6 \mathrm{H}_{2} \mathrm{O}$ and PAR at $25 \pm 0.5{ }^{\circ} \mathrm{C}$ and $\mathrm{I}=0.1 \mathrm{~mol} \mathrm{~L}^{-1}$ $\mathrm{KNO}_{3}$ ) with standard solution of $\mathrm{NaOH}$. The spectral measurements were carried out between 380 and $600 \mathrm{~nm}$ with $6 \mathrm{~nm}$ intervals. The concentrations of [PAR] and $\left[\mathrm{Ni}^{2+}\right.$ to PAR] ratios in final solutions are $4.4 \times 10^{-5} \mathrm{~mol} \mathrm{~L}^{-1}$ and $2: 1,1: 1,1: 2,1: 3,1: 4$, respectively. Then $\mathrm{pH}$ is adjusted in the range of 2-13 by adding hydrochloric acid and sodium hydroxide in titration vessel. By considering the $\mathrm{K}_{\mathrm{sp}}$ of $\mathrm{Ni}(\mathrm{OH})_{2}, 5.48 \times 10^{-16}$ and the maximum $\mathrm{Ni}^{2+}$ concentration in the solutions in one hand and the visual inspection and absorbance readings and normal trend of the spectral profiles it is very unlikely to have precipitation and/or detectable hydrolysis of the $\mathrm{Ni}(\mathrm{OH})_{2}$ in the titration course.

\section{Computer hardware and software}

All absorption spectra were digitized and transferred in ASCII format to an Athlon 2000 XP computer for 
analysis. Data treatment was done with MATLAB for Windows (Mathworks, Version 6.5). The computer program EQUISPEC was written in MATLAB by $M$. Maeder and co-workers. ${ }^{17}$

\section{Results and Discussion}

The electronic absorption spectra of PAR in aqueous solution at various $\mathrm{pH}$ values at $6 \mathrm{~nm}$ intervals in the range 380-600 nm were recorded. Sample spectra of PAR at different $\mathrm{pH}$ values are shown in Figure 1. The principal component analysis of all absorption data obtained at various $\mathrm{pH}$ 's shows at least four significant factors. This claim is, also, supported by the statistical indicators method that has been recently developed by Elbergali et al. ${ }^{18}$ which has predicted four distinguishable components in the samples. These four factors are attributed to the four differently protonated species of a triprotic acid such as PAR $\left(\mathrm{PAR}^{2-}, \mathrm{HPAR}^{-}, \mathrm{H}_{2} \mathrm{PAR}, \mathrm{H}_{3} \mathrm{PAR}^{+}\right)$. This may not be concluded by inspection of visible spectra of PAR.

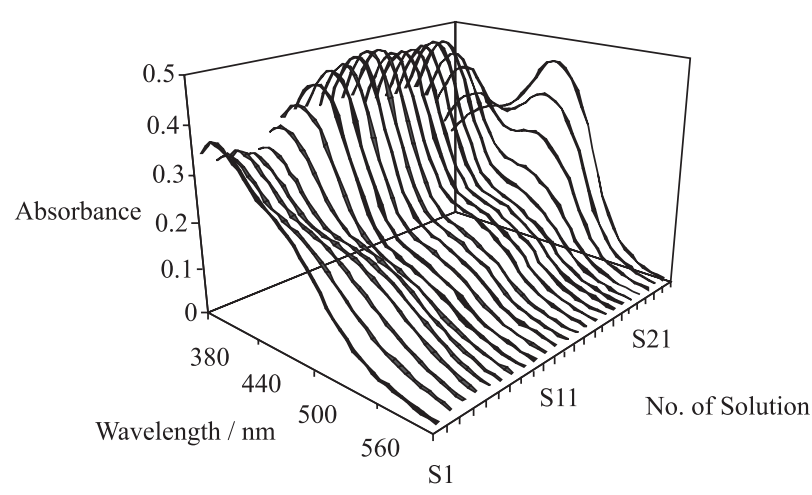

Figure 1. Absorption spectra of PAR at different $\mathrm{pH}$ values: (S1) 2.02, (S2) 2.52, (S3) 3.00, (S4) 3.52, (S5) 4.01, (S6) 4.50, (S7) 5.04, (S8) 5.52, (S9) 6.02, (S10) 6.51, (S11) 7.01, (S12) 7.50, (S13) 8.03, (S14) 8.50, (S15) 9.08, (S16) 9.52, (S17) 10.01, (S18) 10.54, (S19) 11.03, (S20) 11.52, (S21) 12.01, (S22) 12.55, (S23) 13.01.

The protonation constants values of PAR were investigated in 23 different $\mathrm{pH}$ at $25{ }^{\circ} \mathrm{C}$ and $\mathrm{I}=0.1 \mathrm{~mol} \mathrm{~L}^{-1}$ $\left(\mathrm{KNO}_{3}\right)$. Acidity constants of PAR were evaluated using EQUISPEC program from corresponding absorption spectral-pH data. The results of the global analysis quite closely approximate the values reported by Ghasemi and co-workers (Table 1) 19,20 and some critical evaluated reported data by IUPAC. ${ }^{21}$ The obtained distribution diagrams are shown in Figure 2a. The calculated pure spectra of different species of PAR are shown in Figure $2 \mathrm{~b}$.

The absorption spectra were measured at different initial conditions (different $\mathrm{Ni}$ to PAR ratio and each ratio was selected independently) in the desirable $\mathrm{pH}$ range, which are suitable for simultaneous analysis to overcome any probable linear dependency between species. The used ratios were $0: 1,2: 1,1: 1,1: 2,1: 3$ and $1: 4$. Each ratio results in $\mathrm{pH}$-absorption data that are useful in identifying the predominant species formed from metal, ligand and proton. For example in metal rich ratios the species like ML and/or MHL are predominant and in ligand rich ratios the $\mathrm{ML}_{2}$ and $\mathrm{MHL}_{2}$ are main species. With attention to previous published data $^{22,23}$ about the system under study ones has a trivial task to choose more useful metal to ligand ratios. In this

Table 1. Values of $\log K$ for the protonation of PAR reported in the literature compared with those obtained using global analysis at $25{ }^{\circ} \mathrm{C}$ and $\mathrm{I}=0.1 \mathrm{~mol} \mathrm{~L}^{-1}\left(\mathrm{KNO}_{3}\right)$

\begin{tabular}{lcc}
\hline $\log K$ & Reported $^{19}$ & Global analysis \\
\hline $\mathrm{H}+\mathrm{L}^{-2} \leftrightarrow \mathrm{HL}^{-}$ & 12.04 & $12.08 \pm 0.05$ \\
$\mathrm{H}+\mathrm{HL}^{-} \leftrightarrow \mathrm{H}_{2} \mathrm{~L}$ & 5.50 & $5.48 \pm 0.09$ \\
$\mathrm{H}+\mathrm{H}_{2} \mathrm{~L} \leftrightarrow \mathrm{H}_{3} \mathrm{~L}^{+}$ & 3.07 & $2.98 \pm 0.19$ \\
\hline
\end{tabular}
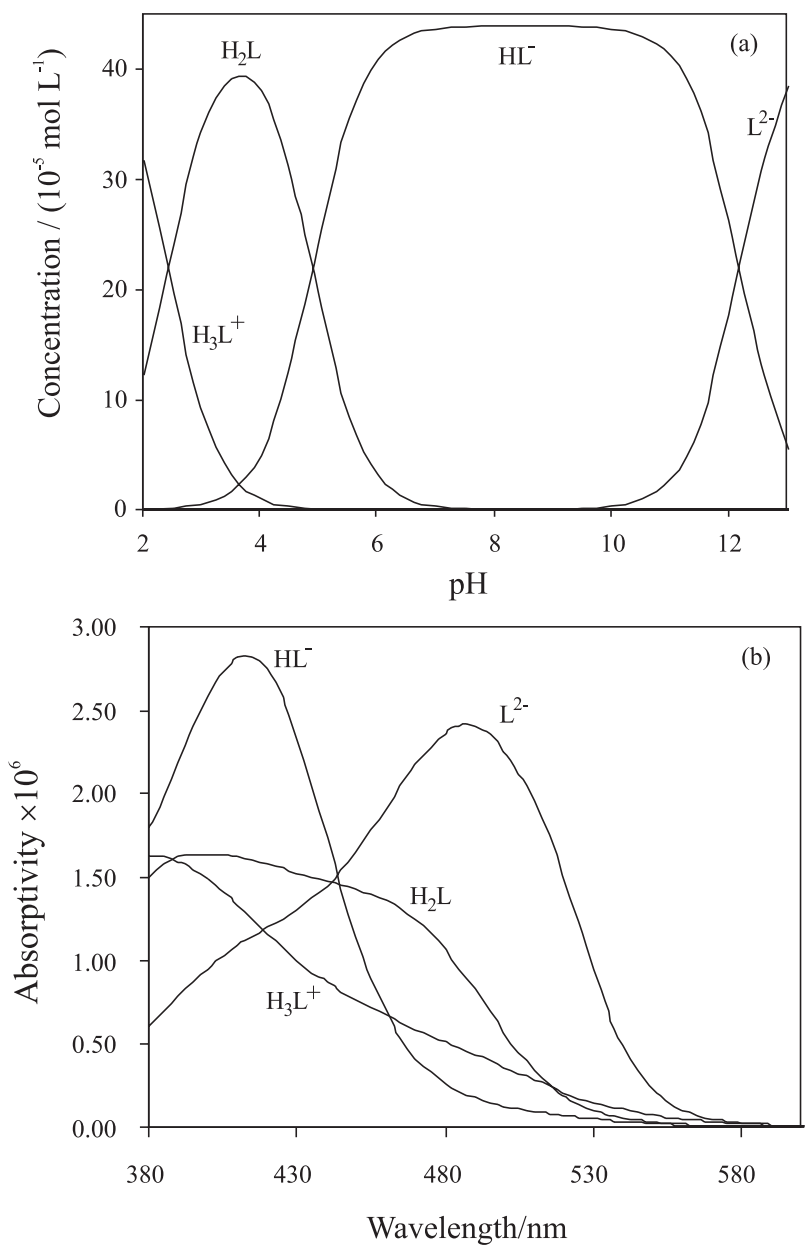

Figure 2. (a) Distribution of major species of PAR, $\mathrm{H}_{3} \mathrm{~L}^{+}, \mathrm{H}_{2} \mathrm{~L}, \mathrm{HL}^{-}$and $\mathrm{L}^{-2}$, as function of $\mathrm{pH}$ for the spectral data of Figure 1 and (b) Molar absorptivities spectra of different form of PAR. 
Table 2. Logarithms of overall formation constants at $25^{\circ} \mathrm{C}$ and $\mathrm{I}=0.1 \mathrm{~mol} \mathrm{~L}^{-1}\left(\mathrm{KNO}_{3}\right)$

\begin{tabular}{|c|c|c|c|c|}
\hline Reaction (charge omitted for brevity) & Ref. 21 & Ref. 22 & Ref. 23 & Global Analysis \\
\hline $\mathrm{M}+\mathrm{L} \leftrightarrow \mathrm{ML}$ & & 13.61 & 14.05 & $13.04 \pm 0.17$ \\
\hline $\mathrm{M}+2 \mathrm{~L} \leftrightarrow \mathrm{ML}_{2}$ & 22.1 & 27.58 & & $26.51 \pm 0.39$ \\
\hline $\mathrm{M}+\mathrm{H}+\mathrm{L} \leftrightarrow \mathrm{MHL}$ & & 20.46 & 21.75 & $19.27 \pm 0.15$ \\
\hline $\mathrm{M}+\mathrm{H}+2 \mathrm{~L} \leftrightarrow \mathrm{MHL}_{2}$ & & 35.62 & & $34.71 \pm 0.33$ \\
\hline $\mathrm{M}+2 \mathrm{H}+2 \mathrm{~L} \leftrightarrow \mathrm{MH}_{2} \mathrm{~L}_{2}$ & & 42.29 & & $41.04 \pm 0.29$ \\
\hline
\end{tabular}

study, since the PAR shows a behavior like a tridentate ligand we inferred the suitable ratios were $0: 1,1: 1$ and 1:2 (metal:ligand). The entire absorption spectra-pH data were analyzed globally and the results of the global analysis for complexation of Ni-PAR system summarized in Table 2. The previous reported values ${ }^{21-23}$ of the system on Ni-PAR in the same conditions, with respect to ionic strength and temperature, are also inserted in Table 2 for simplicity of the comparison.

As it can be seen from the Table 2 the results of the global analysis of Ni-PAR system, from this report, are nearly the same as the previously obtained values and the differences are within the experimental and measurement errors. Ohyoshi ${ }^{23}$ has detected MHL and ML species that expected because in the method the total concentrations of the metal ion is much higher than PAR in all titration steps. On the other hand there are metal rich solutions of two components and this prevent to formation of ligand rich species like $\mathrm{ML}_{2}$ and $\mathrm{MHL}_{2}$ and/or $\mathrm{MH}_{2} \mathrm{~L}_{2}$. Langova et al. ${ }^{22}$ have also reported complexation of Ni-PAR system in $30 \%(\mathrm{v} / \mathrm{v})$ of ethanol solution. They selected species $\mathrm{ML}, \mathrm{ML}_{2}$, MHL, $\mathrm{ML}_{2} \mathrm{H}$ and $\mathrm{ML}_{2} \mathrm{H}_{2}$ as final chemical model, according to residual sum of squared, which is the same with selected final model by global analysis. The observed difference between the stability constants of the present work with reported values by Langova $e t$ $a l .{ }^{22}$ is due to changing of the solvent from pure water to $30 \%(\mathrm{v} / \mathrm{v})$ ethanol-water. The ethanol with lower solvating ability in Guttmann donocity scale ${ }^{24}$ with respect to the water may is responsible of these expected differences.

Figures $3 a$ and $3 b$ show the distribution diagrams for each Ni-PAR measurement after global analysis. Dependences between complex species vary enough between measurements for successful cumulative analysis. The distribution diagram shows the principal species in different ranges of $\mathrm{pH}$. At mole ratio 1:1 (metal ion to ligand), the main species are ML and MHL and in mole ratio $1: 2$, in acidic region, the main species are $\mathrm{MHL}$ and $\mathrm{MH}_{2} \mathrm{~L}_{2}$ and at higher $\mathrm{pH}$ the main species are $\mathrm{MHL}_{2}$ and $\mathrm{ML}_{2}$. The pure spectra of the above
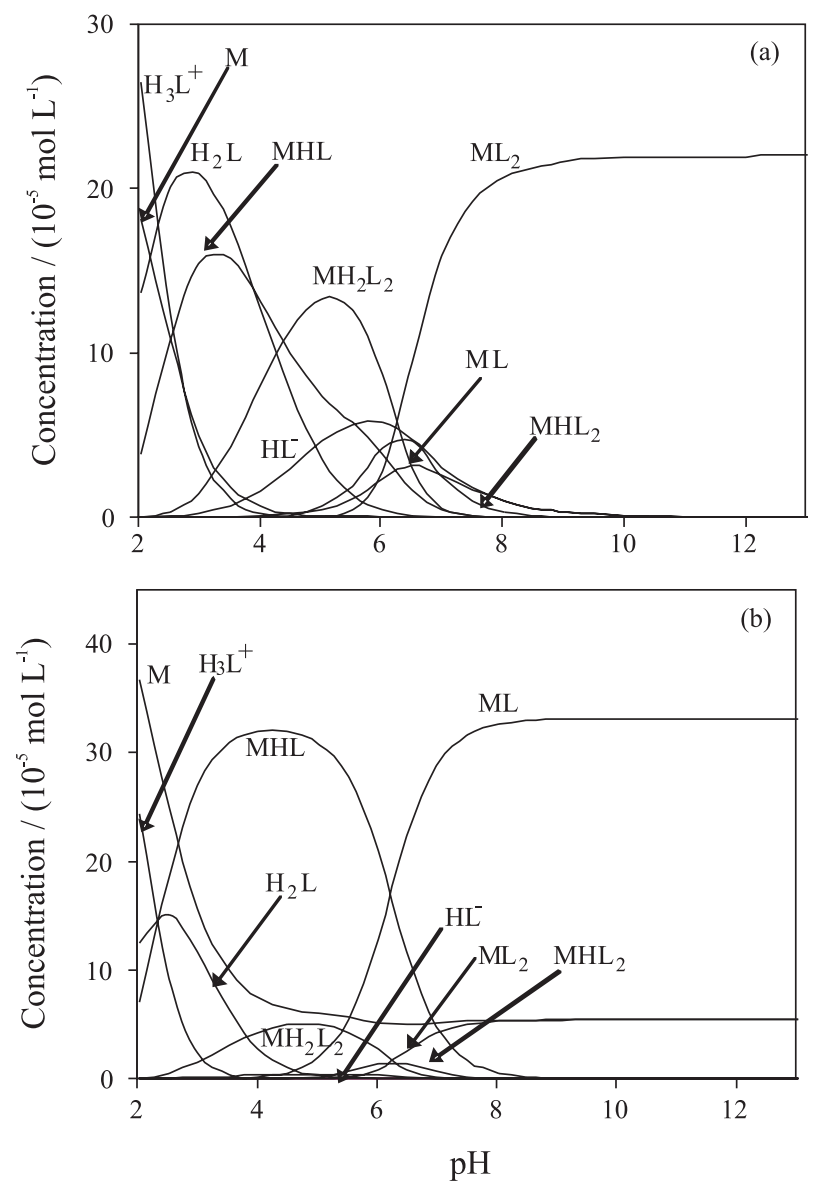

Figure 3. Distribution curve for Ni:PAR ratios of (a) 1:2 and (b) 1:1 measurement simultaneously analyzed.

species and other species obtained by this method are given in Figure 4. It is interesting to note that the spectral traces of the protonated complexes, MHL, $\mathrm{MHL}_{2}$ and $\mathrm{MH}_{2} \mathrm{~L}_{2}$ are similar to spectral profile of $\mathrm{H}_{2} \mathrm{~L}$ or $\mathrm{HL}$ and spectral traces of deprotonated complexes, $\mathrm{ML}$ and $\mathrm{ML}_{2}$, are like to the $\mathrm{L}$ or fully deprotonated ligand molecules.

The notation indicates that the Scheme 2 is the structure of the ML complex. Protonation of ML, $\mathrm{ML}_{2}$ and $\mathrm{ML}_{2} \mathrm{H}$ then occurs at the other free phenolate oxygen. If this is the case only relatively small changes in the absorption spectra is expected upon protonation. This is 


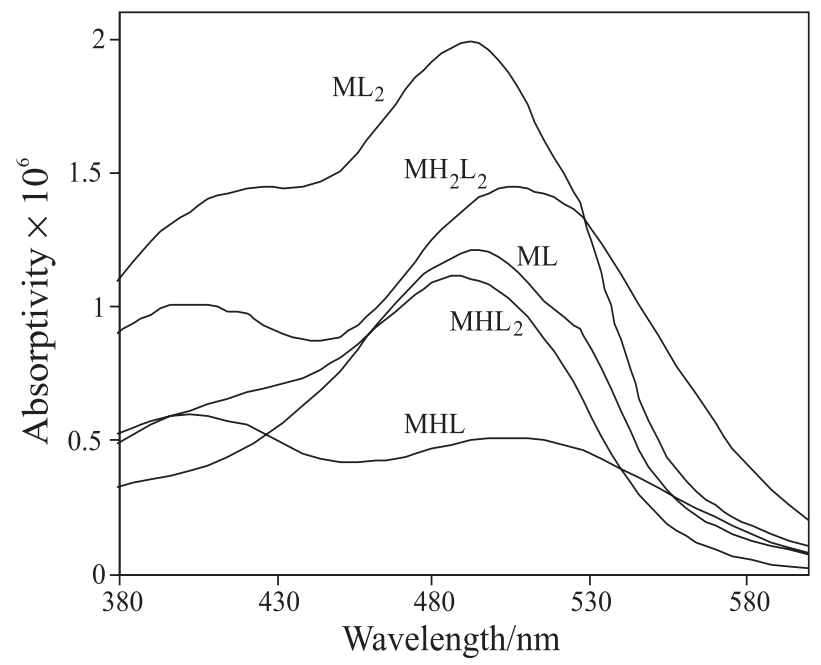

Figure 4. Molar absorptivities for Ni(II)/PAR complexes over the applied wavelength range.

supported by Figure 4 and this is what we actually use the spectral information to say something about the structure. For example the acidity constants obtained from the following equilibria are very similar and is in line with second $\mathrm{p} K_{\mathrm{a}}$ value of PAR around 6.2-6.3.

$\mathrm{ML}+\mathrm{H} \leftrightarrow \mathrm{MHL}$

$\mathrm{ML}_{2}+\mathrm{H} \leftrightarrow \mathrm{MHL}_{2}$

$\mathrm{MHL}_{2}+\mathrm{H} \leftrightarrow \mathrm{MH}_{2} \mathrm{~L}_{2}$

It is not surprising to mention again that these types of information can not be obtained by analysis of the potentiometric titration data.

\section{Conclusion}

In this work, the behavior of protonation and $\mathrm{Ni}$ (II) complexation of 4-(2-pyridylazo) resorcinol in ionic strength $0.1 \mathrm{~mol} \mathrm{~L}^{-1} \mathrm{KNO}_{3}$ at $25^{\circ} \mathrm{C}$ has been studied by a multiwavelenth spectrophotometric method. EQUISPEC is a computer program using the matrix based MATLAB environment for second order global analysis of spectrophotometric equilibrium data. According to the analysis, important complexes are as below: ML, MHL, $\mathrm{ML}_{2}, \mathrm{MHL}_{2}$ and $\mathrm{MH}_{2} \mathrm{~L}_{2}$, which results and obtained formation constants using global analysis are in accordance with reported results.

\section{References}

1. Almasifar, D.; Forghaniha, A.; Khojasteh, Z.; Ghasemi, J.; Shargi, H.; Shamsipur, M.; J. Chem. Eng. Data 1997, 42, 1212.
2. Martell, A. E.; Hancock, R. D.; Metal Complexes in Aqueous Solutions, Plenum Press: New York, 1996.

3. Dunnick, J. K.; Fowler, B. A.; Seiler, H. G.; Sigel, H.; Sigel, A.; Handbook on Toxicity of Inorganic Compounds, Marcel Dekker: New York, 1988.

4. Catsch, A.; Harmuth-Hoene, A. E.; Pharmacol. Ther. A 1976, 1,1 .

5. Gampp, H.; Haspra, D.; Maeder, M.; Zuberbuhler, A. D.; Inorg. Chem. 1984, 23, 3724.

6. Martell, A. E.; Motekaities, R. J.; Determination and Use of Stability Constants, Verlag Chemie: Weinheim, 1988.

7. Meloun, M.; Havel, J.; Hogfeldt, E.; Computation of Solution Equilibria, Ellis Horwood: Chechester, 1988.

8. Polster, J.; Lachmann, H.; Spectrometric Titrations, Verlag Chemie: Weinheim, 1989.

9. Bevington, P. R.; Data Reduction and Error Analysis for the Physical Sciences, McGraw-Hill: New York, 1969.

10. Golub, G. H.; Van Loan, C. F.; Matrix Computations, $2^{\text {nd }}$ ed., John Hopkins University Press: Baltimore, 1989.

11. Press, W. H.; Vetterling, W. T.; Teukolsky, S. A.; Flannery, B. P.; Numerical Recipes in C, Cambridge University Press: Cambridge, 1995.

12. Bugnon, P.; Chottard, J. C.; Jestin, J. L.; Bung, B.; Laurenczy, G.; Maeder, M.; Merbach, A. E.; Zuberbuhler, A. D.; Anal. Chim. Acta 1994, 298, 193.

13. Knutson, J. R.; Beechem, J. M.; Brand, L.; Chem. Phys. Lett. 1983, 102, 501.

14. Beechem, J. M.; Methods Enzymol. 1992, 210, 37.

15. Janssens, L. D.; Boens, N.; Ameloot, M.; De Schryver, F. C.; J. Phys. Chem. 1990, 94, 3564.

16. Beechem, J. M.; Hass, E.; Biophys. J. 1989, 55, 1225.

17. Dyson, R. M.; Kaderli, S.; Lawrance, G. A.; Maeder, M.; Zuberbuhler, A. D.; Anal. Chim. Acta 1997, 353, 381.

18. Elbergali, A.; Nygren, J.; Kubista, M.; Anal. Chim. Acta 1999, $379,143$.

19. Ghasemi, J.; Niazi, A.; Kubista, M.; Elbergali, A.; Anal. Chim. Acta 2002, 455, 335.

20. Ghasemi, J.; Ahmadi, Sh.; Kubista, M.; Forootan, A.; J. Chem. Eng. Data 2003, 48, 1178.

21. Hulanicki, A.; Glab, S.; Ackermann, G.; Pure Appl. Chem. 1983, $55,7$.

22. Langova, M.; Simek, Z.; Chroma, J.; Sommer, L.; Collect. Czech. Chem. Commun. 1987, 52, 878.

23. Ohyoshi, E.; Polyhedron 1986, 5, 1165.

24. Guttmann, V.; Coordination Chemistry in Nonaqueous Solutions, Springer: New York, 1960.

Received: April 27, 2006

Web Release Date: February 15, 2007 